\title{
The Cervical Spine Study Group anterior cervical plate nomenclature
}

\author{
Regis W. Haid, M.D., Kevin T. Foley, M.D., Gerald E. Rodts, M.D., \\ AND BRYAN BARNES, M.D. \\ Department of Neurosurgery, Emory University School of Medicine, Atlanta, Georgia; and \\ Department of Neurosurgery, University of Tennessee-Memphis, Tennessee
}

\begin{abstract}
The authors review historical and biomechanical aspects of anterior cervical plate (ACP) systems. They propose a novel classification system for ACPs based on the biomechanical and graft-loading properties of these systems.

A retrospective review of the literature comprising both clinical and laboratory investigations regarding the $\mathrm{ACP}$ system was undertaken. Comparison of each system is considered in the context of the biomechanical attributes and graft-loading properties of each type of plate. Salient characteristics reviewed include restriction of screw backout, screw-angle variability, and mobility at the screw-plate interface. A new classification system for ACPs is proposed that primarily considers the ability of the construct to restrict screw backout, as well as the properties of the plate-screw interface - that is, the capacity for rotational or translational movement.

A new classification system is presented that provides unified, biomechanically descriptive nomenclature. Using this nomenclature, the ACP devices currently available and those developed in the future can be uniformly categorized.
\end{abstract}

KEY WORDS • ANTERIOR CERVICAL PLATE • ClASSIFICATION • SPINE STABILIZATION

Over the past decade, a seemingly exponential proliferation of plate devices for ACF has occurred. Previously a controversial procedure, ACF in which plates are implanted, has gained widespread acceptance and represents a substantial percentage of the typical spine surgeon's practice. Some debate still exists, however, regarding the exact indications and optimum plate-related design for the wide range of clinical situations requiring $\mathrm{ACF}$.

Anterior cervical fusion was first performed by Bailey and Badgley in the early 1950s. ${ }^{1}$ Cloward, Smith, Robinson, and others advanced the techniques of cervical fusion, but pseudarthrosis rates for multilevel procedures were as high as $40 \%$, even when external orthotic devices were used. ${ }^{8,9,31,38}$ High rates of pseudarthrosis and high rates of kyphotic deformity in multilevel anterior cervical procedures created a need for an anterior internal cervical fixation device. The development of the first anterior plate and screw system by Bohler in 1964 set into motion an evolution of $\mathrm{ACP}$ designs in an effort to provide optimum anterior internal fixation for the cervical spine. ${ }^{3}$

Anterior cervical plates have been purported to improve both fusion rates and outcome in patients undergoing multilevel anterior cervical procedures and may increase fu-

Abpreviations used in this paper: $\mathrm{ACF}=$ anterior cervical fusion; $\mathrm{ACP}=$ anterior cervical plate; $\mathrm{CSLP}=$ cervical spine locking plate. sion rates in certain patients in whom single-level fusion is performed. ${ }^{4-6,10,12,14,17,19-21,25,27,33-37}$ Features that have been cited include earlier patient mobilization, decreased orthotic need, increased loading force applied to the graft, diminished incidence of graft dislodgment, and an improved ability to correct and/or prevent spinal deformity. ${ }^{12,14,17,18,21}$ The ability of a given plate to permit these functions may vary according to the different pathological entities, the type of construct being implanted, and the properties of the plate system itself. Despite the number of variables involved in determining whether an $\mathrm{ACP}$ will be effective in stabilizing a spine and creating arthrodesis, there is no uniform method for classifying plate-related characteristics and matching them to patient requirements.

The authors seek to delineate the evolution of ACPs, review their current indications and biomechanical attributes, and propose a novel nomenclature for their universal description based on biomechanical principles.

\section{EVOLUTION OF ACP SYSTEMS}

\section{Unrestricted Backout Devices}

Discussion of unrestricted backout devices for the anterior cervical spine is mostly a historical footnote, because the vast majority of ACPs used today are fashioned using a restricted backout design. 
The development of the Caspar and Orozco plate systems in the early 1980s represented the introduction of the first widely commercially available ACP system (Fig. 1). These plating systems were nonlocking and nonrigid; in other words, screw angulation was determined entirely according to individual patient needs and the surgeon's preference. ${ }^{5,6,23}$ These two attributes created a cantilevertype system in which there was no fixed moment arm, allowing for subsidence of the construct because of lack of fixation at the screw-plate interface. ${ }^{6,16,29}$ Biomechanically, the graft was thought to share the compressive force caused by this subsidence and thus be exposed to greater compression; as a result of the law of Wolff, the graft would thus have a greater chance of fusing. 7,15,16

The main disadvantages of the Caspar and Orozco plate systems were that the nonlocking and nonrigid (variableangle) screws led to high rates of screw backout and

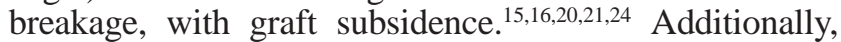
C-arm fluoroscopy was required for bicortical screw purchase, and lower cervical regions were often difficult to visualize fluoroscopically in obese individuals. Overall, the Caspar and Orozco systems were not constrained, that is, nonrigid, because of the significant motion allowed at the plate-screw interface (Fig. 2).

\section{Restricted, Constrained Devices}

The next major development in ACP constructs was the Synthes CSLP, developed in Europe by Morscher in the 1980s and introduced into the United States by Synthes in the early $1990 \mathrm{~s}^{16,22}$ (Fig. 3). The CSLP did not require bicortical screw purchase because of the use of a titanium expansion screw that rigidly fixed the screw to the plate. ${ }^{22,26}$ The CSLP varied biomechanically from the Caspar construct in that there was a predetermined (rigid) screw trajectory and screw purchase was unicortical. The CSLP system was advantageous for several reasons: relative ease of application, lack of requirement for $\mathrm{C}$-arm fluoroscopy, and locking screws, which greatly reduced the incidence of screw backout. ${ }^{16,20,27,32}$ The original plate was wide and difficult to contour, especially at the C2-3 level. Typically, the caudal screw was oriented directly perpendicular to the plate while the rostral screw was angled $12^{\circ}$ caudally, allowing for more optimum screw purchase compared with that achieved using the Caspar system. In recent versions of the Synthes system, the curvature radius for the system has been reduced from 25 to $15 \mathrm{~mm}$.

In early series the plates were more rigid and yielded a higher incidence of screw fracture. ${ }^{20,21}$ The original plates

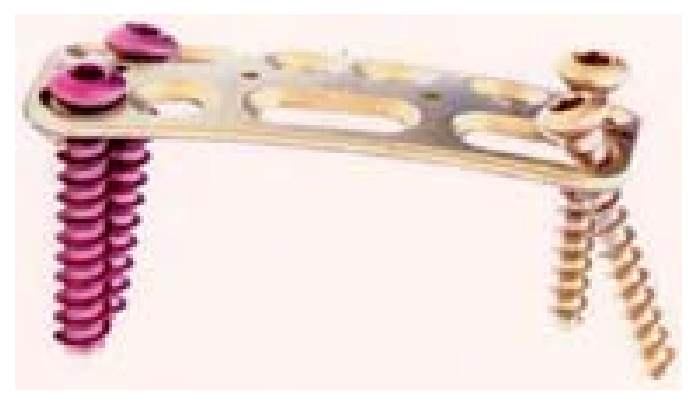

Fig. 1. Photograph showing the lateral view of the Caspar plate.

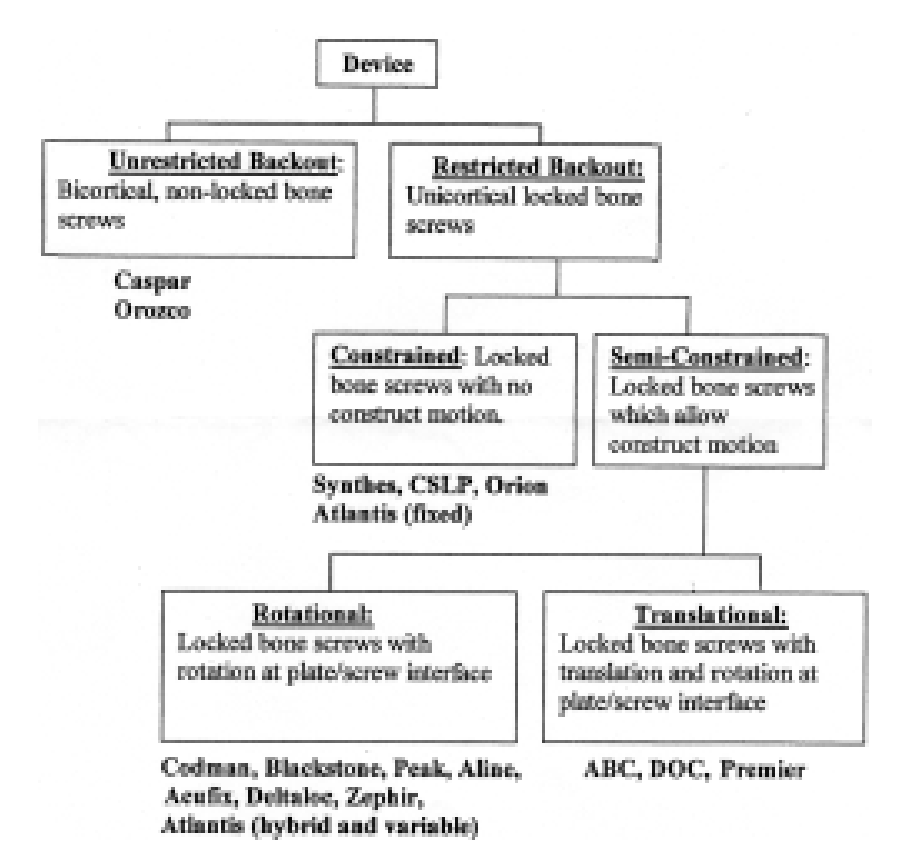

Fig. 2. Classification system for ACP constructs.

were not precontoured for lordosis, which sometimes resulted in loss of sagittal balance unless meticulous plate bending was performed. ${ }^{21}$

The Orion plating system was developed after the Synthes and offered variable-length screws, from 10 to 26 $\mathrm{mm}$, allowing the surgeon to choose between uni- and bicortical screw purchase. Orion plates were also manufactured with a prebent lordosis to help in the restoration of sagittal balance and to provide an optimum bone-plate interface (Fig. 4). Screw angles were fixed similarly to those in the Synthes construct, with a drill guide that locked to the plate. Orion systems locked both the rostral and caudal screws at $15^{\circ}$ rostral and caudal, respectively. The screws were also angled $6^{\circ}$ degrees medially, permitting a "toenailing" effect that theoretically prevented caudal pullout. Orion screws were 4-mm tapered screws, the advantage of which was a redistribution of stress from the

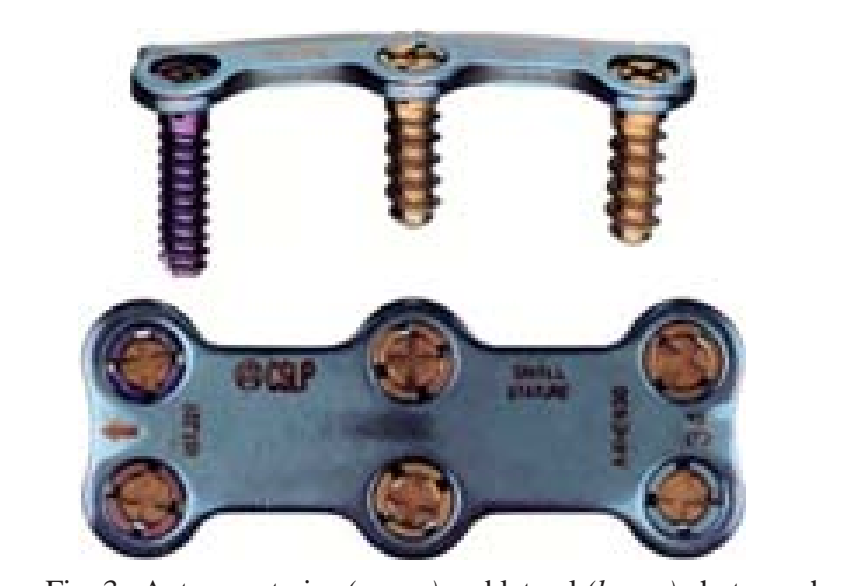

Fig. 3. Anteroposterior (upper) and lateral (lower) photographs of the Synthes CSLP, a constrained, restricted backout device. 
Anterior cervical plate nomenclature

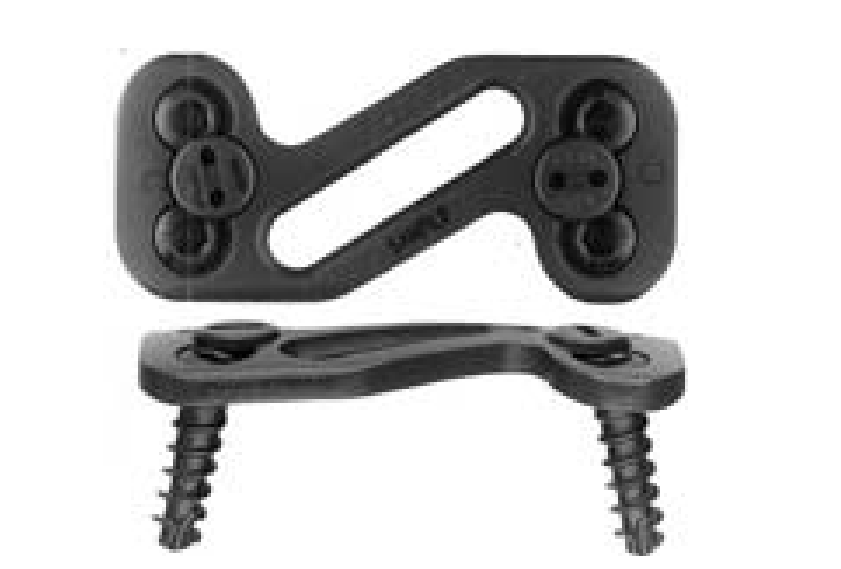

Fig. 4. Anteroposterior (upper) and lateral (lower) photographs of the Orion plate.

screw-plate interface to the full length of the screw (unpublished data). Tapered screws greatly diminished screw breakage.

The length of the plate in the Orion system was generally shorter than its predecessors, thus preventing screws from purchasing in the superior or inferior endplates.

The Orion plate was generally considered to yield excellent results in cases of trauma, but many surgeons believed the device was too rigid (unpublished data). Lowery and McDonough ${ }^{20}$ with associates (unpublished data) obtained results using the Orion system and found a high rate of pseudarthrosis (12\%) in cases of single-level anterior cervical discectomy and fusion. Experimental studies performed in cadaveric models have demonstrated that the Orion plate increased stiffness and diminished motion after corpectomy but also excessively loads the graft in extension, which can cause construct failure. ${ }^{11}$

We believe that in this rigid system, the plate absorbed much of the construct's stress, which in turn decreased the amount of compressive force on the graft. As the Wolff law dictates, less compressive force on the graft would tend to inhibit fusion. Although considered very rigid, excellent results have been demonstrated using the Orion system. ${ }^{21,30}$

The Atlantis ACP system may be used as a restricted, constrained device if all screws are fixed and rigid (Fig. 2 ). Any fixed system may be preferable for use in cases of trauma, although this remains unproven.

\section{Semiconstrained, Rotational Devices}

The Codman plate system was developed to allow for variability in screw direction and to prevent screw backout. Both rostral and caudal screws were designed so that variable screw trajectories could be used, and a built-in cam-locking system was incorporated to reduce the rate of screw backout ${ }^{21,28}$ (Fig. 5). The design of the screw-plate interface is such that graft subsidence through a "pivot" or "rotational" mechanism was developed, thereby increasing load on the graft and allowing for its controlled subsidence. This system mandates rotation of all screws-rostral, caudal, and intermediate.

Excellent outcomes in patients who received the Codman and other similar types of semiconstrained, rotational plates (Fig. 2) have been reported for short- and inter-

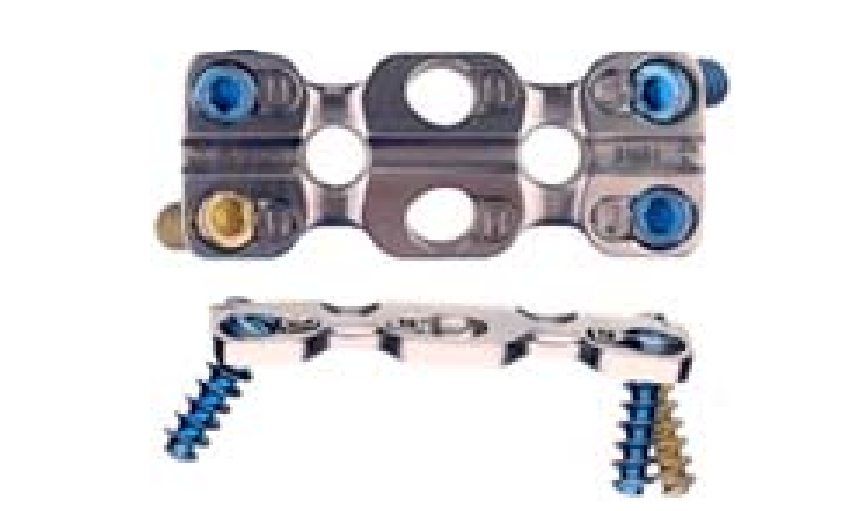

Fig. 5. Anteroposterior (upper) and lateral (lower) photographs showing the Codman plate, an example of a semiconstrained, rotational device. Note the variable-angle screws and cam-locking device.

mediate-segment fixation. ${ }^{21}$ We have found that most cases of Codman plate-related failures tend to occur in multilevel corpectomies or in unstable spines in which there is no additional posterior fixation. ${ }^{23}$ In these circumstances, excessive rotation can lead to graft dislodgment. ${ }^{14,21,28}$ The Atlantis system can also be configured as a semiconstrained, rotational plate, if all screws used are variable.

The aforementioned purely rotational devices are probably best used in cases requiring one- or two-level discectomy and fusion, although additional studies are needed to confirm this.

\section{Semiconstrained, Translational Devices}

Acromed's development of the DOC anterior cervical stabilization system marked the first so-called "translational" cervical stabilization system. The screws in the DOC system are not designed to pivot but instead slide along a rail. The screws are generally rigid at the caudal end but slide at the cephalad end (Fig. 6).

The ABC plating system produced by Aesculap is both a rotational and translational system that closely mimics

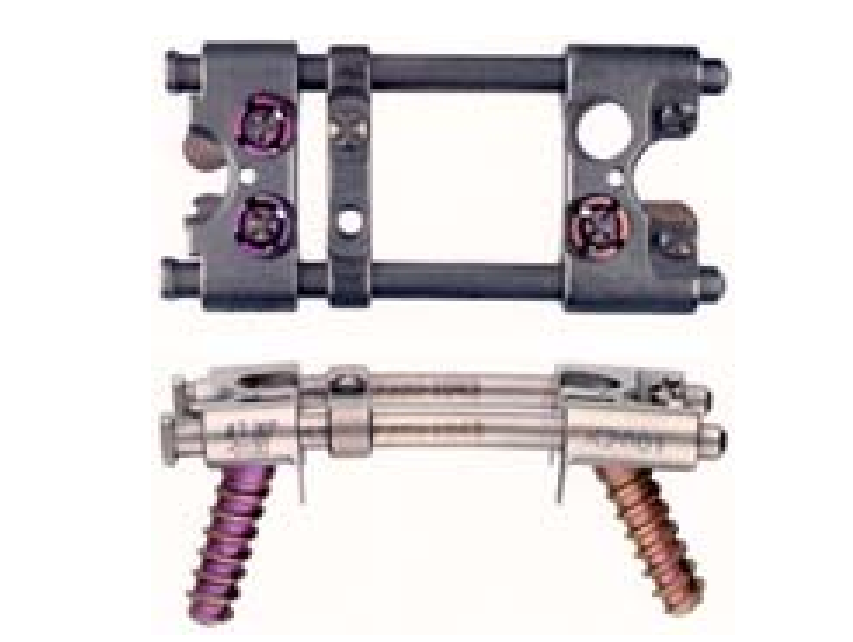

Fig. 6. Anteroposterior (upper) and lateral (right) photographs of the DOC plate device. Translation at the plate-screw interface allows for graft subsidence and loading. 
the Caspar system in the sense that it uses variable-angle bicortical screws (Fig. 7). The ABC and Premier (Sofamor Danek) systems, however, also allow for translational motion of the screw similar to that in the DOC system, thereby combining translation and rotation at the screw-plate interface (Fig. 8). Screws first translate in a slot and may then rotate after maximum translation.

We have found that there is a paucity of peer-reviewed literature exclusively involving outcomes for the aforementioned semiconstrained, rotational devices; the recent development of these systems will undoubtedly lead to long-term outcome studies in the near future.

\section{Multiconstruct System}

The designers of the Atlantis ACP system endeavored to incorporate the most beneficial aspects of several types of cervical plate designs, striving to provide customized biomechanics for a wide range of clinical scenarios. The most unique aspect of the Atlantis system is the use of either a variable-angle (nonfixed) cantilever screw or a fixed-angle cantilever screw (Fig. 9). Depending on the anatomical requirements in a given case, the surgeon may create a rigid construct (similar to the Orion or CSLP), a pivot rotational construct (similar to the Codman plate), or a "hybrid" construct with both fixed and rigid qualities. The Atlantis system also features a floating washer design that prevents screw backout.

As illustrated in Fig. 9, a fixed Atlantis construct uses two fixed-angle screws, creating a rigid construct that is constrained, thus allowing for no rotation or translation. Screws are angled at $12^{\circ}$ cephalad/caudad and $6^{\circ}$ medially. We have found that the rigid construct is most useful when treating patients with unstable cervical lesions such as those induced by trauma.

The variable Atlantis construct uses two sets of variable-angle screws and allows rotational motion of both the superior and inferior sets of screws at the screw-plate interface, similar to the Codman plate system. The variable-angle construct thus creates a semiconstrained plating system, which allows for screw-related movement relative to the plate at both the caudal and cranial ends.

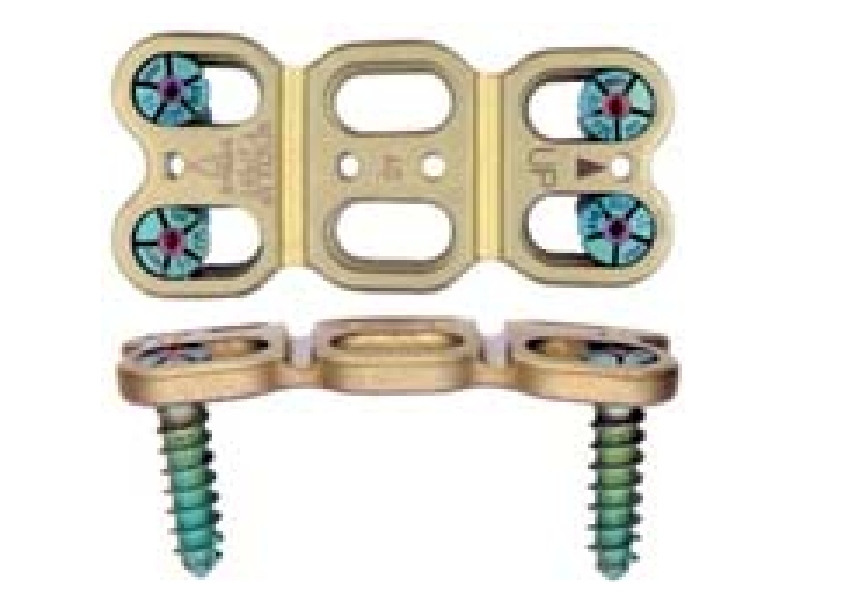

Fig. 7. Anteroposterior (left) and lateral (right) views of the $\mathrm{ABC}$ system. This device allows for rotation and translation at the plate-screw interface.

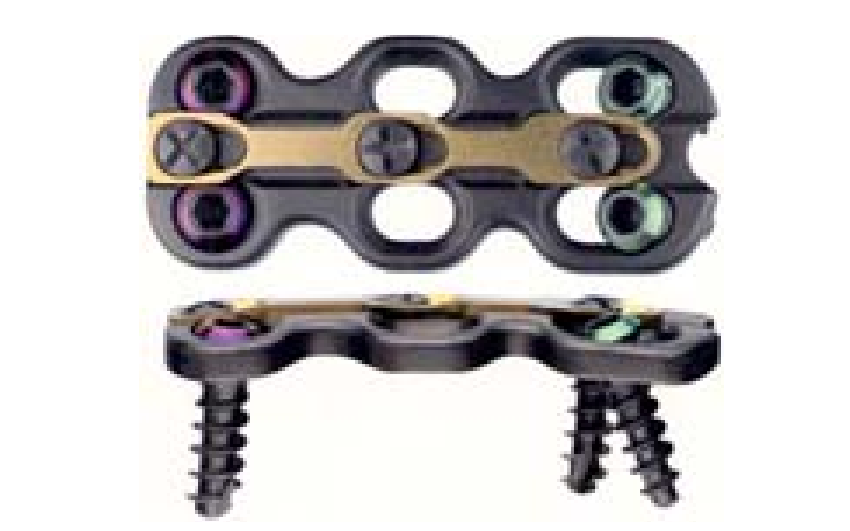

Fig. 8. Anteroposterior (upper) and lateral (lower) views of the Premier plate. This device is similar to the ABC system in allowing both rotation and translation at the plate-screw interface.

The hybrid Atlantis construct uses fixed-angle screws at the inferior portion of the construct and variable-angle screws at the superior aspect of the construct. Biomechanically, the advantage of this construct is that it allows for "controlled subsidence;" that is, the superior variableangle screws are allowed to pivot because of the rotational or translational motion at the superior plate-screw interface. In this way, the graft between the cervical vertebrae is subjected to compressive forces as the construct settles. Graft loading may occur by rotation of the screw relative

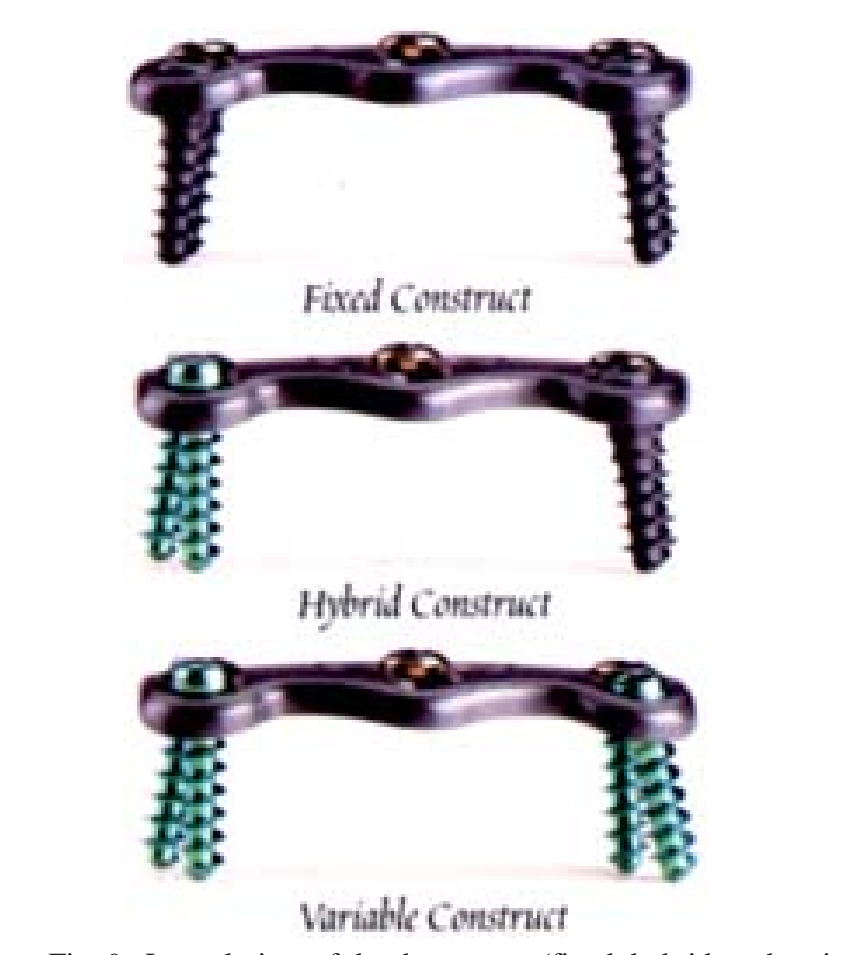

Fig. 9. Lateral view of the three types (fixed, hybrid, and variable) of Atlantis constructs. Note that the fixed screws at the caudal end of the hybrid plate act as a buttress, allowing for rotation only at the variable screws at the superior portion of the construct. Additionally, in the variable construct rotation at both ends of the plate is allowed at the plate-screw interface. 


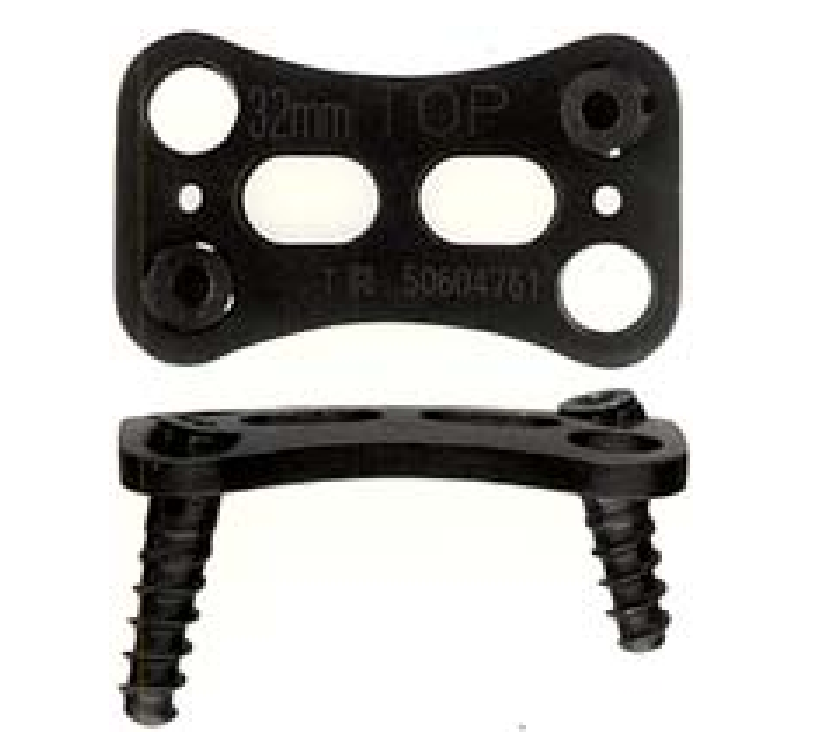

Fig. 10. Anteroposterior (upper) and lateral (lower) views of the Aline plate, a semiconstrained, rotational device.

to the plate or by translation of the screw relative to the plate. It is unclear if translation or rotation at the screwplate interface is the critical element in graft loading.

We have found that the hybrid Atlantis construct meets the requirements in a majority of cases in which anterior cervical corpectomies and discectomies have been performed for the treatment of cervical spondylosis and myelopathy. Fusion rates and clinical outcomes associated with the Atlantis system match or exceed results obtained using other plating systems. . $^{2,13}$

\section{A NEW ACP CLASSIFICATION SYSTEM}

We contend that all cervical plates and constructs available today provide reasonable biomechanical stabilization, whereas the optimal use for each type of system depends on the individual pathological process. Specifically, we contend that cervical plates behave differently biomechanically. As previously mentioned, the proliferation in types of $\mathrm{ACP}$ systems has resulted in an occasionally confusing array of available plates. We propose a novel system of nomenclature, which will help to reduce confusion and provide a common language applicable to current and future ACP designs.

We believe that plates should be classified according to several key features, which describe allowable motion at the plate-screw interface (Fig. 2). The classification system takes into account the historical development of the plate, while recognizing that not all anterior cervical stabilization systems are plates. We also acknowledge that the proposed system of classification is not based on biomechanical testing. Finally, our classification system omits some factors that influence various anterior cervical stabilization constructs, such as plate thickness and screw length.

In the first facet of classification, devices that allow for unrestricted backout, such as the Caspar and Orozco cervical fixation systems, are differentiated from those that restrict backout (Fig. 2). The advantage of unrestricted backout includes allowance for high levels of graft loading related to construct subsidence. The disadvantages of unrestricted backout include higher rates of screw backout and breakage because of significant motion at the platescrew interface. Fluoroscopy is also required for bicortical screw purchase.

The development of restricted screw backout represents the second arm of our first classification tier (Fig. 2). In the Orion and CSLP systems screw backout is restricted by locking the screw to the plate, creating fixed screw angulation into the vertebral body and constraining motion at the plate-screw interface. Systems such as Aline (Surgical Dynamics, Inc.) (Fig. 10), Codman, and Atlantis hybrid constructs have restricted screw backout but allow screws to rotate relative to the plate, thereby producing variable screw angulation and not fully constrained motion at the plate-screw interface. We therefore subclassify restricted backout systems as semiconstrained or constrained (Fig. 2).

Plating systems that restrict backout and are semiconstrained are of three types: rotational, translational, and combined (rotational/translational) (Fig. 2). Examples of a semiconstrained rotational plate include the Codman, Aline, and Atlantis (variable construct) systems, which allow rotational motion of the plate-screw interface, creating variable angulation of the screws. Development of the DOC system created a semiconstrained system that allowed translation of the screw relative to the longitudinal moment arm.

The ABC and Premier systems are examples of restricted backout semiconstrained plating systems that allow for both rotational and translational motion at the screw-plate interface, although they are primarily translational.

\section{CONCLUSIONS}

All currently available cervical plates provide reasonable biomechanical stabilization if tailored to the correct clinical situation. When a construct fails, either the patient is noncompliant or the surgeon has failed to understand adequately requirements dictated by the patient's disease so that the plating system could be tailored to these biomechanical requirements.

We hope that our proposed system of nomenclature will introduce a common language that will allow surgeons to compare clinical outcomes and biomechanical variations among anterior cervical fixation devices. Such comparisons will help in the choice of the optimum anterior fixation for a given pathological entity.

\section{Acknowledgments}

The concepts discussed in this manuscript are the result of the collaborative efforts among the members of the Cervical Spine Study Group: Richard Fessler, M.D., Ph.D., Kevin Foley, M.D., Gerald Rodts, M.D., Regis Haid, M.D., Iain Kalfas, M.D., Stephen Papadopoulos, M.D., Rick Sasso, M.D., Volker Sonntag, M.D., Vincent Traynelis, M.D., and Thomas Zdeblick, M.D.

\section{Disclosure}

Doctors Foley and Rodts both have significant interest in Medtronic Sofamor Danek. Doctor Haid has significant financial interest in Codman, Johnson and Johnson, as well as Medtronic Sofamor Danek. 


\section{References}

1. Baily R, Badgley C: Stabilization of the cervical spine by anterior fusion. J Bone Joint Surg Am 42:565-594, 1960

2. Barnes B, McLauglin M, Rodts GE, Haid RW: Early results using the Atlantis anterior cervical plate system. Neurosurg Focus 12 (1):Article 13, 2002

3. Bohler J, Gaudernak T: Anterior plate stabilization for fracturedislocations of the lower cervical spine. J Trauma 20: 203-205, 1980

4. Bose B: Anterior cervical fusion using Caspar plating: analysis of results and review of the literature. Surg Neurol 49:25-31, 1998

5. Caspar W, Barbier DD, Klara PM: Anterior cervical fusion and Caspar plate stabilization for cervical trauma. Neurosurgery 25:491-502, 1989

6. Caspar W, Geisler FH, Pitzen T, et al: Anterior cervical plate stabilization in one- and two-level degenerative disease: overtreatment or benefit? J Spinal Disord 11:1-11, 1998

7. Chen IH: Biomechanical evaluation of subcortical versus bicortical screw purchase in anterior cervical plating. Acta Neurochir 138:167-173, 1996

8. Cloward RB: The anterior approach for removal of ruptured cervical discs. J Neurosurg 15:602-617, 1958

9. Cloward RB: Treatment of acute fractures and fracture-dislocations of the cervical spine by vertebral-body fusion. J Neurosurg 18:201-209, 1961

10. Connolly PJ, Esses SI, Kostuik JP: Anterior cervical fusion: outcome analysis of patients fused with and without anterior cervical plates. J Spinal Disord 9:202-206, 1996

11. DiAngelo DJ, Foley KT, Vossel KA, et al: Anterior cervical plating reverses load transfer through multilevel strut-grafts. Spine 25:783-795, 2000

12. Emery SE, Bohlman HH, Bolesta MJ, et al: Anterior cervical decompression and arthrodesis for the treatment of cervical spondylotic myelopathy. Two to seventeen-year follow-up. J Bone Joint Surg Am 80:941-951, 1998

13. Epstein NE: The management of one-level anterior cervical corpectomy with fusion using Atlantis hybrid plates: preliminary experience. J Spinal Disord 13:324-328, 2000

14. Epstein NE: The value of anterior cervical plating in preventing vertebral fracture and graft extrusion after multilevel anterior cervical corpectomy with posterior wiring and fusion: indications, results, and complications. J Spinal Disord 13:9-15, 2000

15. Griffith SL, Zogbi SW, Guyer RD, et al: Biomechanical comparison of anterior instrumentation for the cervical spine. J Spinal Disord 8:429-438, 1995

16. Grubb MR, Currier BL, Shih JS, et al: Biomechanical evaluation of anterior cervical spine stabilization. Spine 23:886-892, 1998

17. Kaiser MG, Haid RW Jr, Subach BR, et al: Anterior cervical plating enhances arthrodesis following discectomy and fusion with cortical allograft. Neurosurgery (In press)

18. Katsuura A, Hukuda S, Imanaka T, et al: Anterior cervical plate used in degenerative disease can maintain cervical lordosis. J Spinal Disord 9:470-476, 1996

19. Kostuik JP, Connolly PJ, Esses SI, et al: Anterior cervical plate fixation with the titanium hollow screw plate system. Spine 18: 1273-1278, 1993

20. Lowery GL, McDonough RF: The significance of hardware failure in anterior cervical plate fixation. Patients with 2- to 7-year follow-up. Spine 23:181-187, 1998

21. Mayr MT, Subach BR, Comey CH, et al: Cervical spinal stenosis: outcome after anterior corpectomy, allograft reconstruction, and instrumentation. J Neurosurg 96 (Spine 1):10-16, 2002
22. Morscher E, Sutter F, Jenny H, et al: Die vordere Verplattung der Halswirbelsaule mit dem Hohlschrauben-Plattensystem aus Titanium. Chirurg 57:702-707, 1986

23. Orozco Delclos R, Llovet Tapies R: Osteosintesis en las lesions traumaticas y degeneratives de la columna vertebral. Revista Traumatol Cirurg Rehabil 1:45-52, 1971 (Reference unverified)

24. Panjabi MM, Isomi T, Wang JL: Loosening at the screw-vertebra junction in multilevel anterior cervical plate constructs. Spine 24:2383-2388, 1999

25. Paramore CG, Dickman CA, Sonntag VK: Radiographic and clinical follow-up review of Caspar plates in 49 patients. J Neurosurg 84:957-961, 1996

26. Raveh J, Stich H, Sutter F, et al: Use of titanium-coated hollow screw and reconstruction plate system in bridging of lower jaw defects. J Oral Maxillofac Surg 42:281-294, 1984

27. Rechtine GR, Cahill DW, Gruerenberg M, et al: The synthes cervical spine locking plate and screw system in anterior cervical fusion. Tech Orthop 9:86-91, 1994

28. Rengachary SS, Sanan A: Anterior stabilization of the cervical spine using locking plate systems, in Wilkins RH, Rengachary SS (eds): Neurosurgery. New York: McGraw-Hill, 1996, pp 2983-2986

29. Richman JD, Daniel TE, Anderson DD, et al: Biomechanical evaluation of cervical spine stabilization methods using a porcine model. Spine 20:2192-2197, 1995

30. Schultz KD Jr, McLaughlin MR, Haid RW Jr, et al: Singlestage anterior-posterior decompression and stabilization for complex cervical spine disorders. J Neurosurg 93 (Spine 2): 214-221, 2000

31. Smith GW, Robinson RA: The treatment of certain cervical spine disorders by anterior removal of the intervertebral disc and interbody fusion. J Bone Joint Surg Am 40:607-624, 1958 (Reference unverified)

32. Spivak JM, Chen D, Kummer FJ: The effect of locking fixation screws on the stability of anterior cervical plating. Spine 24: 334-338, 1999

33. Suh PB, Kostuik JP, Esses SI: Anterior cervical plate fixation with the titanium hollow screw plate system. A preliminary report. Spine 15:1079-1081, 1990

34. Swank ML, Lowery GL, Bhat AL, et al: Anterior cervical allograft arthrodesis and instrumentation: multilevel interbody grafting or strut graft reconstruction. Eur Spine J 6:138-143, 1997

35. Wang JC, McDonough PW, Endow K, et al: The effect of cervical plating on single-level anterior cervical discectomy and fusion. J Spinal Disord 12:467-471, 1999

36. Wang JC, McDonough PW, Endow KK, et al: Increased fusion rates with cervical plating for two-level anterior cervical discectomy and fusion. Spine 25:41-45, 2000

37. Wang JC, McDonough PW, Kanim LE, et al: Increased fusion rates with cervical plating for three-level anterior cervical discectomy and fusion. Spine 26:643-647, 2001

38. White AA III, Southwick WO, Deponte RJ, et al: Relief of pain by anterior cervical-spine fusion for spondylosis. A report of sixty-five patients. J Bone Joint Surg Am 55:525-534, 1973

Manuscript received November 16, 2001.

Accepted in final form December 11, 2001.

Address reprint requests to: Bryan Barnes, M.D., Department of Neurosurgery, Emory University School of Medicine, 1365 B Clifton Road, NE, Suite 6400, Atlanta, Georgia 30022. email: bbarn01 @emory.edu. 